\title{
Bimaxillary Advancement as the Initial Treatment of Obstructive Sleep Apnea: Five Years Follow-Up of the Pori Experience
}

\author{
Antti Raunio $^{1}$, Esa Rauhala ${ }^{1}$, Minna Kiviharjư ${ }^{1}$, Ossi Lehmijoki ${ }^{1}$, George K. B. Sándor ${ }^{1}$, Kyösti \\ Oikarinen ${ }^{1}$
}

${ }^{1}$ Department of Oral and Maxillofacial Surgery, Institute of Dentistry, University of Oulu, Oulu, Finland.

\author{
Corresponding Author: \\ Antti Raunio, \\ Institute of Dentistry, University of Oulu \\ Box 5281, FIN-90014, Oulu \\ Finland \\ Phone: +358-537-5439 \\ Fax: $+358-537-5560$ \\ E-mail: antti.raunio@oulu.fi
}

\begin{abstract}
Objectives: Bimaxillary advancement surgery has proven to be effective treatment of obstructive sleep apnea syndrome. According to the Stanford protocol upper airway soft tissue surgery or advancement of tongue by chin plastic surgery is first carried out and if obstructive sleep apnea persists, then bimaxillary advancement is done. This study describes the 5 year outcome of 13 obstructive sleep apnea patients in whom the Stanford protocol was omitted and bimaxillary advancement was carried out as initial surgical treatment.

Material and Methods: Patients were divided in two groups. Group A comprised patients with obstructive sleep apnea (OSAS) confirmed by polysomnography in whom ODI-4 (oxygen desaturation index) was 5 or more. Group B consisted of patients with occlusal problems needing orthognathic surgery and with OSAS symptoms but no clear disease on polysomnography, where the ODI-4 index was less than 5. Both groups were treated with bimaxillary advancement surgery (BAS) as initial therapy.

Results: In the group A mean ODI-4 was 17.8 (SD 12) before treatment and 3.5 (SD 3.4) at 5-year follow-up ( $\mathrm{P}=0.018$ in paired differences t-test). In group B the ODI-4 remained below 5. In group A mean saturation improved from 94.3\% (SD 1.6) to $96.3 \%$ (SD 2), $\mathrm{P}=0.115$ and in group B from $96.3 \%$ (SD 1.2) to $97.8 \%$ (SD 1.7), $\mathrm{P}=0.056$ (in paired differences t-test). The static charge sensitive bed evaluation showed improvement in all patients except one.

Conclusions: Bimaxillary advancement surgery is safe and reliable as an initial surgical treatment of obstructive sleep apnea syndrome.
\end{abstract}

Keywords: sleep apnea, obstructive; sleep-disordered breathing; maxillofacial orthognathic surgery; mandible; LeFort osteotomy; sagittal split ramus osteotomy.

Accepted for publication: 29 March 2012

To cite this article:

Raunio A, Rauhala E, Kiviharju M, Lehmijoki O, Sándor GK, Oikarinen K. Bimaxillary Advancement as the Initial Treatment of Obstructive Sleep Apnea: Five Years Follow-Up of the Pori Experience.

J Oral Maxillofac Res 2012 (Jan-Mar);3(1):e5

URL: http://www.ejomr.org/JOMR/archives/2012/1/e5/v3n1e5ht.pdf

doi: $10.5037 /$ jomr.2012.3105 


\section{INTRODUCTION}

Obstructive sleep apnea syndrome (OSAS) is a rather common disease affecting $4 \%$ of men and nearly $2 \%$ of women between 30 - 60 years of age [1]. In OSAS the upper airway becomes obstructed during sleep causing interruptions in breathing or lowered breathing air flow. Obstructed breathing events may last more than 10 seconds and are called apnea or hypopnea. In most severe cases the patient can suffer from hundreds of apnea events during sleep. These events can be followed with a static charge sensitive bed (SCSB) where different cardio-respiratory functions are monitored [2].

Sleep apnea can be either obstructive, central or a combination of these [3]. In OSAS the predisposing factors include obesity, mandibular retrognathia, tonsillar hypertrophy, nasal obstruction all of which cause a decreased of posterior airway space $[4, \underline{5}]$.

Treatment of OSAS includes preventive methods, use of devices that improve oxygenation of breathing and various surgeries. Weight loss is essential and may be the most important treatment and prevention. The continuous positive air pressure device (CPAP) assists breathing by maintaining patency of the airways of the OSAS patient $[\underline{6}, 7]$.

Surgical treatment modalities include nose surgery, septoplasty, spreader grafts and uvulo-palato-pharygoplasty (UPPP). Advancement of the mandibular insertion of the suprahyoidal muscles improves oxygenation and is achieved by means of genioplasty, by the so called BOX-operation or by means of surgical advancement of the jaws $[\underline{5}, 8]$. The implementation of various surgical treatments is based on the Stanford protocol [5] which divides surgery into two phases.

Phase I includes UPPP and BOX-operations and phase II advancement of maxilla and mandible, often called bimaxillary advancement surgery (BAS). According to the Stanford protocol phase II operations are carried out in those cases where phase I operations do not lead to positive results.

An alternative protocol has been used in the Central Hospital of Satakunta, Pori, Finland, in which phase I is omitted and phase II surgery is carried out as the initial surgical treatment in selected cases. The reason for the Pori-team not to follow the Stanford protocol was the empiric observation that bimaxillary surgery clearly relieves selected patients' symptoms and that the previous results of UPPP and BOX-operations were not very promising in treating severe cases of OSAS. There are reports in the literature that support this notion and many OSAS patients have occlusal and skeletal disharmonies that would require orthognathic surgery $[\underline{8-10}]$.
The aim of this study was to find out how subjective symptoms and polysomnography findings of OSAS patients are influenced by bimaxillary advancement surgery as the initial treatment over a 5-year follow-up period and the outcome of this treatment when used as the initial surgical method in treating OSAS.

\section{MATERIAL AND METHODS}

This study was approved by the Ethical Board of Satakunta Health Care District and was conducted in accordance with the principles of the Helsinki Declaration.

A total of 17 patients, 15 men and 2 women with mean age of 50.9 (SD 7.9) years, were referred to the Central Hospital of Satakunta in southwest Finland for the management of OSAS. All patients suffered from symptoms of OSAS. The pulmonologist was responsible for the comprehensive care of the patients.

All patients were examined at the Pulmonary Department according to a standard protocol including patient interview, registration of general medical status, radiographs such as lateral skull X-ray and polysomnography. Consultations by ear-nose and throat specialists and orthodontists were also carried out at this stage. The orthodontist confirmed the occlusal diagnosis based on clinical examination and radiographic cephalometric analysis (Table 1). Those patients who failed CPAP trials or splint therapy were sent to the Department of Oral and Maxillofacial Surgery for treatment and treated initially by BAS thus omitting the phase I of the Stanford protocol. BAS included Le Fort I osteotomy and sagittal split ramus osteotomy as described in literature $[\underline{5}, \underline{11}]$. In each case a minimum of a $10 \mathrm{~mm}$ mandibular advancement was carried out. The amount of maxillary advancement was dependent on occlusal relationship. For example two patients with normal occlusion received a mandibular advancement of $10 \mathrm{~mm}$ and a corresponding or matching maxillary advancement of $10 \mathrm{~mm}$ as well. These patients received bimaxillary advancement surgery as they were intolerant of both CPAP and splint therapy.

No splints were left in place after the surgery and no postoperative maxillo-mandibular immobilisation was used. All surgeries were uneventful without complications.

After surgery the patients were followed-up to 5 years. Of the 17 patients one died from unrelated causes and three did not appear at their 5-year followup examination. Thus 13 patients were included in the study illustrating longitudinal results up to 5 years. The polysomnography device used was Biomatt ${ }^{\mathbb{B}}$ (Biorec, Turku, Finland) and the data programme 
Table 1. Statistical summary of preoperative characteristics of patients undergoing bimaxillary advancement surgery due to sleep apnea syndrome (OSAS)

\begin{tabular}{|c|c|c|c|c|c|c|}
\hline \multirow[b]{2}{*}{ Group } & \multicolumn{2}{|c|}{ Gender, \% } & \multirow{2}{*}{$\begin{array}{c}\text { Age, years } \\
\text { M (SD) }\end{array}$} & \multicolumn{3}{|c|}{ Occlusion, $\%$} \\
\hline & Male & Female & & Normal & $\begin{array}{l}\text { Mandibular } \\
\text { retrognathia }\end{array}$ & $\begin{array}{l}\text { Bimaxillary } \\
\text { retrognathia }\end{array}$ \\
\hline$A(n=7)$ & 100 & 66.7 & $52.2(8.3)$ & 28.6 & 57.1 & 14.3 \\
\hline$B(n=6)$ & 0 & 33.7 & $44.0(4.7)$ & 0 & 83.3 & 16.7 \\
\hline P value & \multicolumn{2}{|c|}{$0.2^{\mathrm{a}}$} & $0.03^{b}$ & \multicolumn{3}{|c|}{$\chi^{2}=2.0 ; \mathrm{df}=2 ; \mathrm{P}=0.7^{\mathrm{c}}$} \\
\hline
\end{tabular}

a'By Fisher's Exact Test.

'By Mann-Whitney test.

${ }^{\mathrm{c}}$ By Chi-Square test.

$\mathrm{M}(\mathrm{SD})=$ mean $($ standard deviation $)$.

was Uniblott ${ }^{\circledR}$ (Unesta, Turku, Finland). The results were evaluated by the same clinical neurophysiologist after all tests.

Three parameters of polysomnography were followed by the neurophysiologist in this study. These included ODI-4 (oxygen desaturation index), mean blood oxygen saturation $\left(\mathrm{SaO}_{2}\right)$ and automatic analysis of static charge sensitive bed (SCSB) evaluation. ODI-4 illustrated the number of $4 \%$ or more oxygen desaturations lasting ten seconds or more per hour. The apnea-hypopnea index or AHI was not recorded at the Central Hospital of Satakunta so that the investigators were dependant on the ODI-4. All patients were confirmed to have obstructive sleep apnea syndrome without central sleep apnea by the attending neurophysiologist.

SCSB evaluation was given by clinical neurophysiologist based on different polysomnographic variables and was recorded as: no disease, mild disease, moderate disease or severe disease. In the analysis the patients were divided into two groups:

- Group A comprised of those patients with OSAS that were confirmed by polysomnography and in whom ODI-4 index was 5 or more. None of these patients had occlusal problems but BAS was justified on the bases of OSAS.

- Group B consisted of those patients who had occlusal problem needing orthognathic surgery and with OSAS symptoms but no clear disease on polysomnography, where the ODI-4 index was less than 5 .

Polysomnography was carried out in the hospital ward during the first examination, one year and 5 years after BAS. Patients' interviews before the treatment and at 5 -year follow-up were performed with a standardized questionnaire which was a modification of the Basic Nordic Sleep Questionnaire (BNSQ) [12,13]. BNSQ with 27 different items and 21 questions has been translated into different Scandinavian languages. Questions from BNSQ have been adapted to routine clinical use in Finnish Hospitals [13]. This modification was systemically used in the Central Hospital of
Satakunta and included questions such as "How often do you suffer from daytime tiredness?", "How often do you fall asleep involuntarily?" and "How often are you bothered by nightly arousals?" In these questions the patients were allowed to give alternatives on a 5 degree scale: (1) never or less than once a month, (2) less than once a week, (3) 1 - 2 days a week, (4) 3 - 5 days a week, (5) every day or nearly every day or always or nearly always while sleeping. Additional questions "How difficult the actual sleep apnea symptoms are in your opinion?" and "estimate your sleep quality" were also recorded on a 5 degree scale.

At the five-year examination an extra question "How would you evaluate the influence of the BAS treatment over all on your OSAS disease?" was added. The answers were given similarly on five degree scale where one means the best and five the worst outcome.

\section{Statistical analysis}

The results were tabulated and means and their standard deviations were determined. Where appropriate onesided paired samples t-tests, Fisher's Exact test, MannWhitney test, Chi-Square test and Wilcoxon test were performed to compare pre- and post-operative results.

\section{RESULTS}

Mean age of the patients was 52.2 (SD 8.3) years in the group $\mathrm{A}$ and 44.0 (SD 4.7) years in the group B (Table 1).

Table 2 illustrate preoperative and 5 year's followup results of several polysomnography parameters assessment. The mean ODI-4 was 17.8 (SD 12) before treatment and 3.5 (SD 3.4) at 5-year follow-up $(\mathrm{P}=0.018$ in paired differences $\mathrm{t}$-test). After the treatment five out of seven patients in this group had ODI-4 index under five and the rest two patients were only slightly over this critical level. In the group A 
Table 2. Changes in polysomnography (ODI-4 [events/h], $\mathrm{SaO}_{2}[\%]$ and $\mathrm{BMI}\left[\mathrm{kg} / \mathrm{m}^{2}\right]$ )

\begin{tabular}{|c|c|c|c|c|c|c|c|c|c|}
\hline \multirow[b]{2}{*}{ Group } & \multicolumn{3}{|c|}{ ODI-4 } & \multicolumn{3}{|c|}{$\mathrm{SaO}_{2}$} & \multicolumn{3}{|c|}{ BMI } \\
\hline & Pre & Post & $\begin{array}{c}\text { Paired } \\
\text { differences } \\
\text { P value }^{\mathrm{a}}\end{array}$ & Pre & Post & $\begin{array}{c}\text { Paired } \\
\text { differences } \\
\text { P value }^{\mathrm{a}}\end{array}$ & Pre & Post & $\begin{array}{c}\text { Paired } \\
\text { differences } \\
\text { P value }^{\mathrm{a}}\end{array}$ \\
\hline$A(n=7)$ & $17.8(12.0)$ & $3.5(3.4)$ & 0.018 & $94.3(1.6)$ & $96.3(2.0)$ & 0.115 & $30.9(4.1)$ & $31.0(3.5)$ & 0.500 \\
\hline$B(n=6)$ & $1.6(1.2)$ & $3.0(2.6)$ & 0.465 & $96.3(1.2)$ & $97.8(1.7)$ & 0.056 & $28.1(3.8)$ & $30.2(4.8)$ & 0.138 \\
\hline P value ${ }^{b}$ & 0.001 & 0.945 & & 0.022 & 0.101 & & 0.234 & 0.445 & \\
\hline
\end{tabular}

${ }^{\mathrm{a} B y}$ Wilcoxon test.

${ }^{b}$ By Mann-Whitney test.

$\mathrm{M}(\mathrm{SD})=$ mean (standard deviation).

all patients showed a significant $(\mathrm{P}=0.018)$ improvement of ODI-4 index (Table 2 and Figure 1). In group B the difference was less as the values were initially low and could not therefore have become significantly $(\mathrm{P}=0.465)$ better. In this group the index remained under the critical level five in all cases except one (Table 2 and Figure 1).

Mean oxygen saturation during the follow-up seemed to increase in most patients in both groups (Table 2 and Figure 2). In group A two patients and in group B one patient showed mildly worsened saturation levels. It is remarkable that even in the "no disease" group B the saturation level generally improved (Figure 2). In group A mean saturation improved from 94.3\% (SD 1.6) to $96.3 \%$ (SD 2), $\mathrm{P}=0.115$ and in group $\mathrm{B}$ from $96.3 \%$ (SD 1.2) to $97.8 \%$ (SD 1.7), $\mathrm{P}=0.056$ (in paired differences t-test) (Table 2).

The change in body mass index is shown in Table 2. Most patients (11 out of 13) had gained some weight. In group A no changes greater than 5\% were observed. In group $B$ three patients had more than $15 \%$ increase in their BMI, one of them had an increase of BMI by $27.5 \%$.

Analysis of the changes in the SCSB evaluation revealed that four patients were estimated to have some level of disease left at follow-up while all other patients were free of OSAS symptoms. The Cronbach's alpha of the Basic Nordic Sleep Questionnaire was determined to be 0.723 pre-operatively and 0.400 post-operatively. The changes of several subjective findings are shown in Table 3. The amount of satisfaction or dissatisfaction is shown on a 5-degree scale. The results of the five questions made before operation and at follow-up showed improvement in the patient's subjective experience. In the group A only one patient reported worsening of any criteria. Some values remained at preoperative level. In both groups A and B daytime somnolence seemed to improve. In group B the satisfaction with outcome was also high except in one patient. This patient's BMI increased as much as $28 \%$ during the follow-up time.

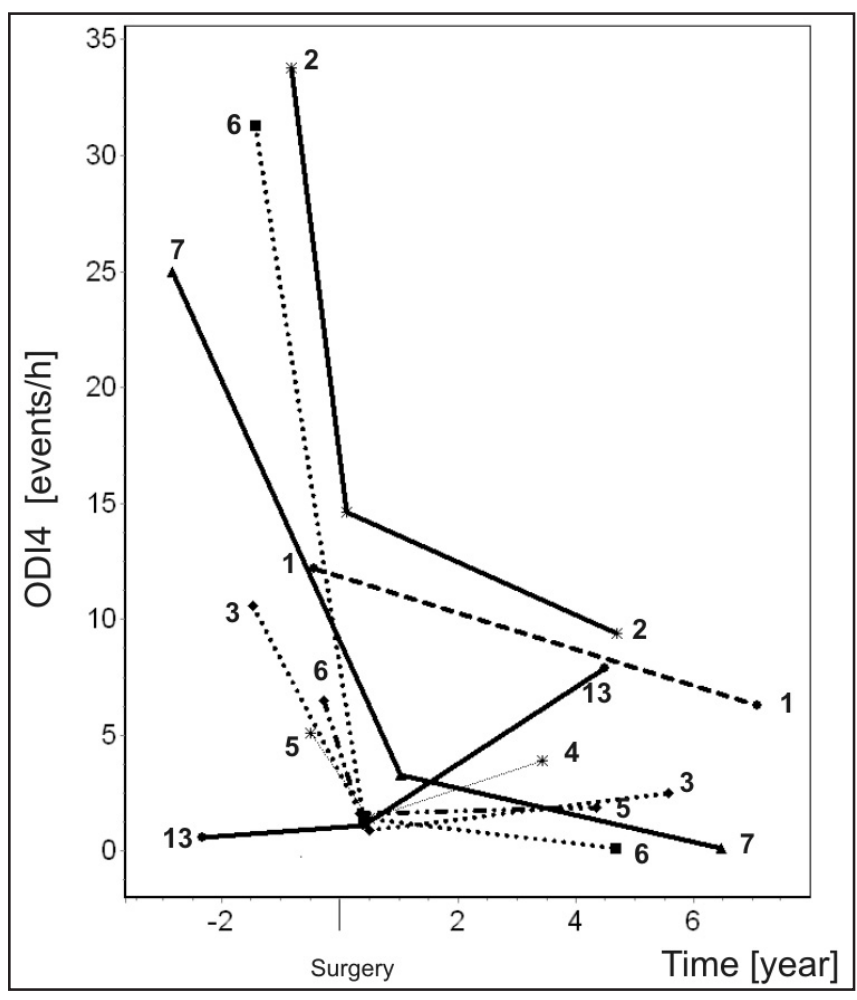

Figure 1. Mean ODI-4 (events/h) of patients before surgery and at various measuring points after surgery. All patients in group A are included. Only patient number 13 in the group B is shown, for other the ODI-4 measurements at all time points are $<5$.

\section{DISCUSSION}

Bimaxillary advancement surgery is an effective treatment modality of OSAS whether it is evaluated by objective methods or by subjective experience. The results also show that the positive results are well maintained over at least the 5-year follow-up period.

The number of patients in the study is rather low which is one weakness of the study. The strength of this study, however, is that the patients were operated by same surgeons by same methods under a relatively short time. There are only few previous studies that report on the long-term results of BAS treatment of OSAS patients. 


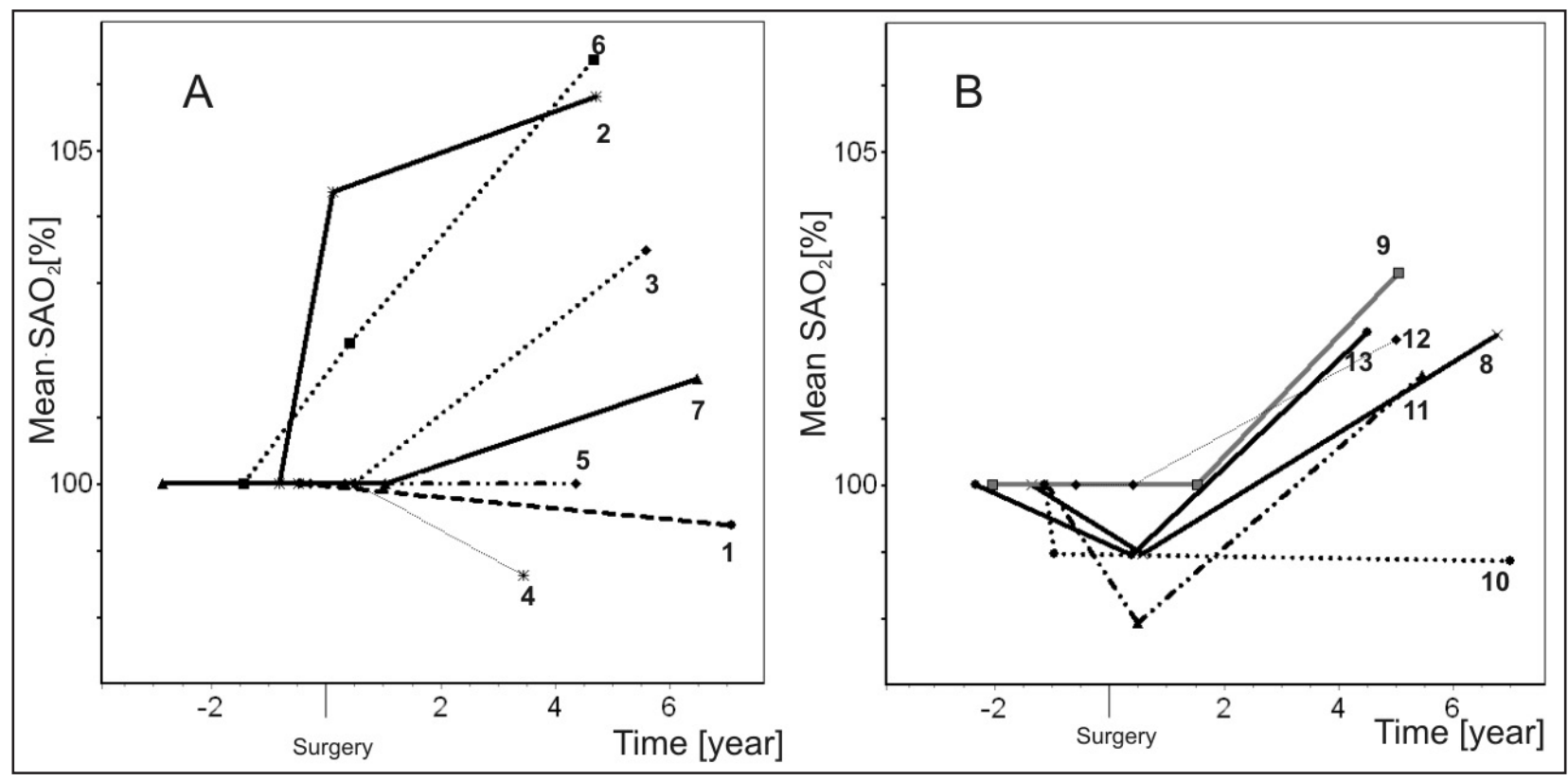

Figure 2. Mean saturation $\left(\mathrm{SAO}_{2}[\%]\right)$ of patients in the groups $\mathrm{A}$ and $\mathrm{B}$ before surgery and at various measuring points after surgery. Initial level is illustrated as 100 and the following measurements are shown in relation to this. Each patient is illustrated separately.

Table 3. Subjective changes in obstructive sleep apnea syndrome (OSAS)

\begin{tabular}{cccccccccccc}
\hline \multirow{2}{*}{ Group } & \multicolumn{2}{c}{ Severity of OSAS } & \multicolumn{2}{c}{ Sleep quality } & \multicolumn{2}{c}{ Daytime tiredness } & \multicolumn{2}{c}{$\begin{array}{c}\text { Involuntary falling } \\
\text { asleep }\end{array}$} & \multicolumn{2}{c}{ Nightly arousals } & $\begin{array}{c}\text { Effect of } \\
\text { therapy }\end{array}$ \\
\cline { 2 - 13 } & \multicolumn{1}{c}{ Pre } & Post & Pre & Post & Pre & Post & Pre & Post & Pre & Post & \\
\hline A & $3.1(1.5)$ & $2.3(1.9)$ & $3.5(1.0)$ & $3.5(.8)$ & $3.9(.9)$ & $3.4(1.0)$ & $3.7(1.1)$ & $3.3(1.1)$ & $2.9(1.3)$ & $2.8(1.2)$ & $1.9(0.7)$ \\
\hline B & $2.8(1.7)$ & $2.8(2.0)$ & $3.5(.8)$ & $2.8(1.1)$ & $3.3(1.2)$ & $2.6(.5)$ & $1.5(.5)$ & $2.6(1.1)$ & $3.5(.5)$ & $0.6(.5)$ & $2.2(0.8)$ \\
\hline
\end{tabular}

$\mathrm{M}(\mathrm{SD})=$ mean (standard deviation).

The results are shown on a 5 degree scale: 1 is the best, 5 the worst. The preoperative and postoperative values were compared using Wilcoxon test. All differences are insignificant $(\mathrm{P}>0.05)$.

This study describes the long-term outcome of OSAS patients in whom the Stanford protocol has been omitted and BAS has been carried out as an initial treatment. In this study we have also been able to follow the outcome of patients who complained of serious sleep apnea symptoms even though the disease was not confirmed by polysomnography (group B). Generally the patients in this group reported satisfaction with the BAS operation. Also blood oxygenation and polysomnography showed clear improvement. This is a new finding in the area of sleep apnea research.

In group $\mathrm{A}$, which contained patients with a confirmed diagnosis of OSAS, the ODI-4 index showed a dramatic fall after operation and remained low or even decreased over the 5 years of follow-up. The authors feel that the maintenance of the positive result is the most important finding of this study. The patients' mean preoperative ODI-4 of 17.8 (SD 12) in group A was lower than reported in some other studies $[10,11,14]$. The postoperative ODI-4 value of 3.5 (SD 3.4) was in accordance with the previously cited studies.
In group B the ODI-4 index was low from the beginning and did not fall further. It is remarkable though, that this index did not become worse despite the aging of the patients.

In group A the oxygen saturation also improved slightly. The preoperative saturation level of $96.3 \%$ (SD 1.2) was relatively high compared with other studies $[10,11,14]$. The saturation in the mentioned studies varied between $92 \%$ and $93 \%$. The increase of the mean saturation from $94.3 \%$ (SD 1.6) to $96.3 \%$ (SD 1.2) in group A and from $96.3 \%$ (SD 2.0) to $97.8 \%$ (SD 1.7) in group B are in coincidence with other studies $[10,11,14]$.

It is also clear that oxygen saturation in group $\mathrm{B}$ increased $(\mathrm{P}=0.056$ in paired differences t-test) and the patients reported improvement in their condition. Group B complained of sleep apnea type symptoms preoperatively but OSAS could not be detected according to ODI-4. Is it possible that sleep apneas themselves are not the only explanation for the disease? The authors suspect that low oxygen saturation without cessation of breathing is one of the reasons for patients' symptoms. 
The ODI-4 index does not register falls in saturation of less than $4 \%$ and these patients did not complain of snoring either pre- or post-operatively.

The increase of oxygen saturation seems to improve the patient's general outcome. This is possibly the explanation for the fact the patients in this group generally felt relief of the disease after the operation. This cannot be measured by ODI-4, which originally was low, falsely indicating that there is no sleep apnea disease.

The influence of increased BMI-value is also very important and should never be underestimated. All patients, who reported negative subjective development of OSAS or showed worsened objective results, have gained weight. This was the fact especially in one patient whose BMI increased 28\% (from 30 to 38 ) during the follow-up and partly explained the increase of his ODI-4. It should also be recognized that this patient informed to have experienced only "some improvement" after the operation. This patient had the greatest increase in BMI value.

The patients` own opinions showed clear satisfaction. Subjectively most patients experienced improvement in their condition or felt that their disease had even become cured due to surgery. Only patients, whose weight had significantly increased, reported uncertainty in this respect. This is in agreement with previous studies $[\underline{3}, 14-16]$.

In group A only one patient reported that BAS had given only slight relief or the situation remained unchanged. In this case the improvement of ODI-4 was considerable, but there was still residual disease. While the SCSB evaluations showed that OSAS disease was still present, the patient's condition was, however, much better than prior to the operation. In this case a 24.4 score decrease in ODI-4 could be observed.

All patients in group B reported increased satisfaction and only two of them reported "some improvement". One of these was the patient in whom the BMI increased by $28 \%$. The patient's SCSB evaluation also showed progression of OSAS. The other case had OSAS neither prior to or after the operation according to SCSB evaluation. He had mandibular retrognathia and subjective sleep apnea symptoms preoperatively. There was another patient whose preoperative SCSB evaluation showed no evidence of disease. Also this patient felt, however, that his condition had significantly improved.

In group B there was one patient, who had some signs of OSAS both pre- and postoperatively. One factor could be that his BMI had increased by $7 \%$.

In the group A daytime tiredness and tendency to fall asleep seemed to have improved. That may be the most important factor for the satisfaction of these patients.
It is paradoxical, however, that one patient showed worse evaluation post-operatively than preoperatively yet his over-all evaluation of the effect of BAS was positive.

In group B also the improved quality of sleep and diminished nightly arousals are to be notified.

Surgical techniques in this study were uniform being performed by one of two surgeons. The authors feel that operative technique can influence the results of this operation and also the sleep apnea parameters. For example during the operations the height of the maxilla was not especially taken into account while according to author's later experiences it has become clear that there is a big difference whether maxilla is lowered or elevated in these surgeries.

By omitting the phase one of the Stanford protocol, the patients 'motivation remains high and results are better accepted as the patients experience less morbidity. If patients have both occlusal problems and sleep apnea symptoms, it is justified to perform bimaxillary surgery, to solve both problems simultaneously. In these cases UPPP and/or Box osteotomy as initial surgical treatment would be less indicated as occlusal problems require surgical treatment in any case. Orthognatic patients who complain of sleep apnea-type symptoms should always be examined, keeping bimaxillary surgery in mind. The patients should undergo a polysomnographic examination. In the presence of sleep apnea symptoms a bimaxillary surgery with approximately $10 \mathrm{~mm}$ advancement of mandible may alleviate OSAS. Also in cases in which the disease is present even though no occlusal discrepancies are observed the "initial" BAS is indicated especially when patient's motivation is high. There are also a great number of OSAS patients who cannot tolerate CPAP treatment and an alternative treatment such as BAS should be available. Professional drivers, for example, are a group where the most efficient method of treatment should be carried out primarily [17]. This can be justified for safety and economic reasons.

\section{CONCLUSIONS}

This study supports earlier findings and experience that BAS is an effective and safe treatment modality of OSAS. According to this study the positive influence of BAS on OSAS as initial surgery is well maintained over a 5 years period. These results support and strengthen the idea of BAS as the initial treatment of obstructive sleep apnea without Stanford Stage I surgery such as UPPP or BOX-operations.

For some unknown reason the BMI of the patients in this study seemed to increase over the duration of 
the follow-up. Some unfavourable changes in the patients' condition can be explained by an increase of BMI. The role of weight gain remains essential in accordance with earlier studies. Patients should receive counselling about the extreme importance of weight loss and for the long-term support to prevent future weight gain in order to protect the outcomes of their sleep apnea surgery.
The influence of different treatment plans and techniques of BAS on OSAS requires further research.

\section{ACKNOWLEDGMENTS AND DISCLOSURE STATEMENTS}

The authors declare that they have no conflict of interest.

\section{REFERENCES}

1. Young T, Palta M, Dempsey J, Skatrud J, Weber S, Badr S. The occurrence of sleep-disordered breathing among middleaged adults. N Engl J Med. 1993 Apr 29;328(17):1230-5. [Medline: 8464434] [doi: 10.1056/NEJM199304293281704] [FREE Full Text]

2. Alihanka J, Vaahtoranta K, Saarikivi I. A new method for long-term monitoring of the ballistocardiogram, heart rate, and respiration. Am J Physiol. 1981 May;240(5):R384-92. [Medline: 7235054]

3. Bell WH. Modern Practice in Orthognathic and Reconstructive Surgery. Philadelphia: WB Saunders; 1992. vol 3: p. 2021-59.

4. Larsson LG, Lundbäck B, Jonsson AC, Lindström M, Jönsson E. Symptoms related to snoring and sleep apnoea in subjects with chronic bronchitis: report from the Obstructive Lung Disease in Northern Sweden Study. Respir Med. 1997 Jan;91(1):5-12. [Medline: 9068811] [doi: 10.1016/S0954-6111(97)90131-1]

5. Strohl KP, Redline S. Recognition of obstructive sleep apnea. Am J Respir Crit Care Med. 1996 Aug;154(2 Pt 1):279-89. Review. [Medline: $\underline{8756795}$ ]

6. Polo O, Berthon-Jones M, Douglas NJ, Sullivan CE. Management of obstructive sleep apnoea/hypopnoea syndrome. Lancet. 1994 Sep 3;344(8923):656-60. Review. [Medline: 7915352] [doi: 10.1016/S0140-6736(94)92089-3]

7. Sullivan CE, Issa FG, Berthon-Jones $\mathrm{M}$, Eves $\mathrm{L}$. Reversal of obstructive sleep apnoea by continuous positive airway pressure applied through the nares. Lancet. 1981 Apr 18;1(8225):862-5. [Medline: 6112294] [doi: 10.1016/S0140-6736(81)92140-1]

8. Conradt R, Hochban W, Brandenburg U, Heitmann J, Peter JH. Long-term follow-up after surgical treatment of obstructive sleep apnoea by maxillomandibular advancement. Eur Respir J. 1997 Jan;10(1):123-8. [Medline: 9032503] [doi: 10.1183/09031936.97.10010123] [FREE Full Text]

9. Hochban W, Hallfeldt U, Brandenburg U. [Surgical treatment of obstructive sleep apnea by modifying the facial skeleton with reference to cephalometric parameters]. Pneumologie. 1993 Mar;47 Suppl 1:194-200. German. [Medline: 8497479]

10. Smatt Y, Ferri J. Retrospective study of 18 patients treated by maxillomandibular advancement with adjunctive procedures for obstructive sleep apnea syndrome. J Craniofac Surg. 2005 Sep;16(5):770-7. [Medline: 16192855] [doi: $10.1097 / 01$. scs.0000179746.98789.0f]

11. Hochban W, Brandenburg U, Peter JH. Surgical treatment of obstructive sleep apnea by maxillomandibular advancement. Sleep. 1994 Oct;17(7):624-9. [Medline: 7846461]

12. Partinen M, Jamieson A, Guilleminault C. Long-term outcome for obstructive sleep apnea syndrome patients. Mortality. Chest. 1988 Dec;94(6):1200-4. [Medline: $\underline{3191760] \text { [doi: 10.1378/chest.94.6.1200] }}$

13. Partinen M, Gislason T. Basic Nordic Sleep Questionnaire (BNSQ): a quantitated measure of subjective sleep complaints. J Sleep Res. 1995 Jun;4(S1):150-155. [Medline: 10607192] [doi: 10.1111/j.1365-2869.1995.tb00205.x] [FREE Full Text]

14. Kessler P, Ruberg F, Obbarius H, Iro H, Neukam FW. [Surgical management of obstructive sleep apnea]. Mund Kiefer Gesichtschir. 2007 Apr;11(2):81-8. German. [Medline: 17406922]

15. Hochban W, Conradt R, Brandenburg U, Heitmann J, Peter JH. Surgical maxillofacial treatment of obstructive sleep apnea. Plast Reconstr Surg. 1997 Mar;99(3):619-26; discussion 627-8. [Medline: 9047179] [doi: 10.1097/00006534-199703000-00002]

16. Prinsell JR. Maxillomandibular advancement surgery for obstructive sleep apnea syndrome. J Am Dent Assoc. 2002 Nov;133(11):1489-97; quiz 1539-40. Review. [Medline: 12462692]

17. Riley RW, Powell NB, Guilleminault C. Obstructive sleep apnea syndrome: a review of 306 consecutively treated surgical patients. Otolaryngol Head Neck Surg. 1993 Feb;108(2):117-25. [Medline: 8441535] 


\section{To cite this article:}

Raunio A, Rauhala E, Kiviharju M, Lehmijoki O, Sándor GK, Oikarinen K. Bimaxillary Advancement as the Initial Treatment of Obstructive Sleep Apnea: Five Years Follow-Up of the Pori Experience.

J Oral Maxillofac Res 2012;3(1):e5

URL: http://www.ejomr.org/JOMR/archives/2012/1/e5/v3n1e5ht.pdf

doi: $10.5037 /$ jomr.2012.3105

Copyright (C) Raunio A, Rauhala E, Kiviharju M, Lehmijoki O, Sándor GK, Oikarinen K. Accepted for publication in the JOURNAL OF ORAL \& MAXILLOFACIAL RESEARCH (http://www.ejomr.org), 29 March 2012

This is an open-access article, first published in the JOURNAL OF ORAL \& MAXILLOFACIAL RESEARCH, distributed under the terms of the Creative Commons Attribution-Noncommercial-No Derivative Works 3.0 Unported License, which permits unrestricted non-commercial use, distribution, and reproduction in any medium, provided the original work and is properly cited. The copyright, license information and link to the original publication on (http://www.ejomr.org) must be included. 